\title{
An Alternative Method of Very Long-term Conservation of Digital Images and their Historical Context for The Archive, University College, Oxford
}

\author{
Graham Diprose \\ Photographer, Author \\ 13 Heathfield Drive \\ Redhill, RH1 5HL, UK \\ grahamdiprose@gmail.com
}

\author{
Michael George \\ Photographer, Author \\ 2 Monterey Close \\ Bexhill-on-Sea, TN39 3SZ, UK \\ info@michaelgeorgephotography.com
}

\author{
Robin Darwall-Smith \\ University College, Oxford \\ High Street \\ Oxford OX1 4BH, UK \\ robin.darwall-smith@univ.ox.ac.uk
}

\begin{abstract}
The fragility of digital data as a means of storing our images, texts and finances, is well-known to anyone who has ever experienced a failed hard drive, with vital work still to be backed up. Curators worldwide are charged with finding means of safely preserving all the born digital and digitised material in their collections. Yet the likelihood that technologies and generally accepted methods for data preservation utilised at the start of their time in post, are likely to be vastly different in every way, later in their career. We are already aware of many of the technical issues faced in longer-term digital preservation, redundant software and file formats, data storage hardware failure, bit rot literally breaking down data over time, to name but a few. However, these may be the least of the issues facing our particular digital works in any archive, supposing there is no funding for further vital migration, or the archive has newer material that is considered more important, or simply that our, yet unborn, great-great-grandchildren have very different aesthetic tastes and do not like or value our particular collection. This paper proposes an alternative approach to very long-term digital preservation where our most important and significant works of art can be safely preserved for centuries into the future, by utilising a proven technology many thousands of years old.
\end{abstract}

Film digitisation. Image restoration. Long-term digital archiving. Curation and accession. Pigment ink printing.

\section{INTRODUCTION}

A chance meeting with photographer Michael George, led to a further meeting, with both Michael and Dr Robin Darwall-Smith, Archivist, University College, Oxford, about how best to conserve a representative body of Michael's work as a photographer, in the Archive of the College, at which he had been an Exhibitioner in English from 1962 to 1965.

Since the preferred film of Michael George in the 1980s and 1990s was Kodachrome 64, exposed and then processed as colour slides, it will be readily understood that we were presented with a particular creative challenge, through both the inherent issues concerning degradation of dyebased film images and difficult previous storage conditions. His original images could not therefore be expected to survive for a greater length of time without digitisation. Recent work by the Image Permanence Institute, Rochester Institute of Technology, describes 'The Vinegar Syndrome' that can affect all cellulose tri-acetate-based films longer term. The decomposing acetate, particularly if stored in a warm, moist place, gives off acetic acid that makes the film distorted and brittle and is highly likely to attack and degrade the colour dyes.

Additionally, Kodachrome film has proven very difficult to scan, even when using state-of-the-art equipment, due to the nature of the particular dyes synthesised during the complex seventeen stages of processing. However carefully digitised, and restored to a very high standard, still did not mean that these newly-created tiff digital data files would achieve any greater longevity for the photographs, than the deteriorating film images themselves. 


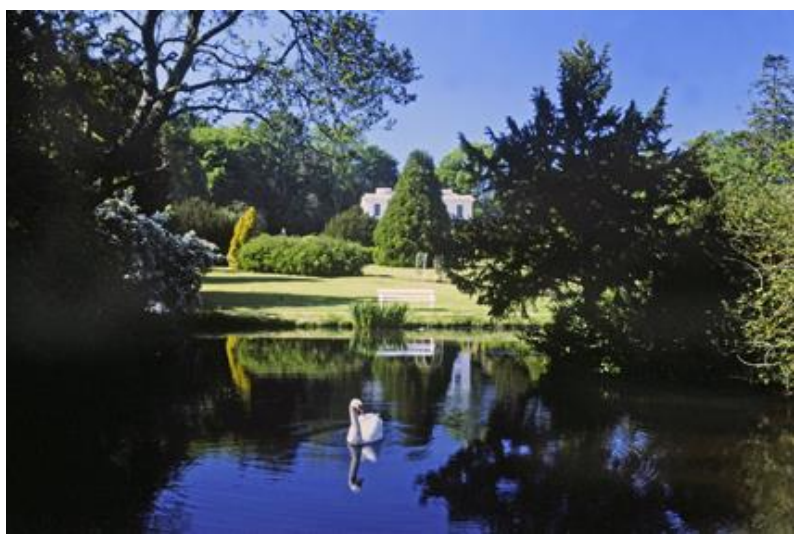

Figure 1: County Louth, Killineer, the lake, 1985 by Michael George.

Digitising photographs certainly offers greater opportunities for exposure to a wider audience via websites or social media. However, it is quite likely that the copying process may have to be repeated from the originals in 25-50 years time if technology changes to the point where migration is too difficult — assuming that the cellulose film lasts that long.

Today, many archivists are receiving digital image files from bequests and donations, often in totally unsuitable file sizes and formats, together with typed or word-processed text, totally incompatible to their own filing systems and that require massive additional work on their part, prior to any accession.

While they may be very confident of preserving actual artefacts, by specifying working in controlled environments, with inert boxes and polyester sleeves, they are rightly concerned about all the known issues in digital data preservation, never mind those that may well be beyond all of our comprehension, in a mere $30-50$ years hence.

We decided to devise a faster and better method of digitising original film images, and then, an innovative approach to very-long-term preservation of digital images and text over centuries, rather than decades into the future. None of us will live to discover if our experiment has been successful. Nevertheless, there may be helpful pointers in this Case Study for small-to-medium-size museums, galleries and individual artists considering verylong-term preservation of their significant artistic works, or digital photographs and their context.

\section{THE FOUR PARTNERS THAT MAKE UP THIS PROJECT}

In 'A Journey Through Ireland', we have been working with a selection of approximately 400 of Michael George's stunning $35 \mathrm{~mm}$ Kodachrome images of the richly varied landscape, historic sites, and heritage gardens of Ireland, for which he has researched and written a fascinating supporting text that often describes in detail the people and places, history and geography. It became a concern of ours that the images would mean very little without this context, if the database holding this information, failed to survive, longer term.

About a third of Michael's images to be archived in this first phase, 'A Journey Through Ireland', had initially been published, with text by the garden designer and historian Patrick Bowe, in their 1986 book, The Gardens of Ireland. While the quality of the finished book overall was good, the image reproduction - on the cusp of the move to digital pre-production - left much to be desired.

We are fortunate indeed to have as partner in this endeavour University College, Oxford, founded by William of Durham in 1249, and considered to be the oldest of the colleges that comprise the University of Oxford. The Archive at 'Univ' has among its many treasures, manuscripts illuminated with pigment paints and inks that date from as far back as the $14^{\text {th }}$ century.

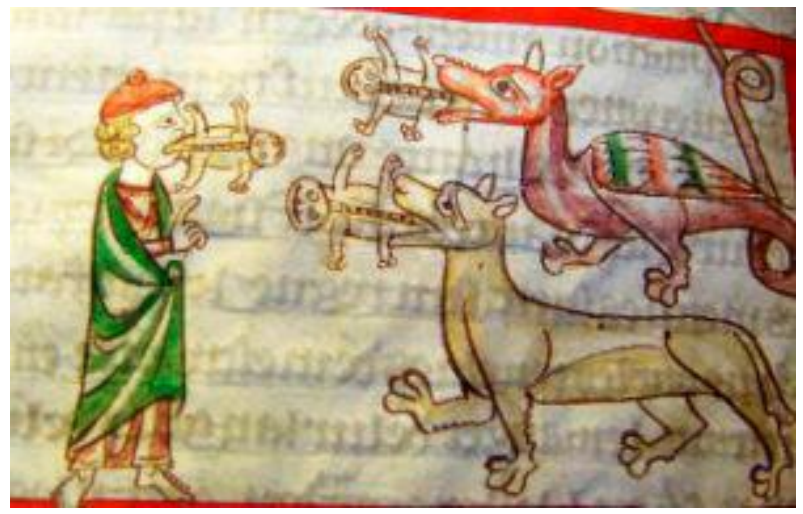

Figure 2: The Apocalypse Manuscripts c.1300 Revelations 16:13-14. (Courtesy of Univ, Oxford.)

We have been keen to avoid any method that is likely to require updating or migrating during the project's long journey into the future, in a way very similar to that of Univ's precious documents, also by our using only pigment inks onto acid-free paper.

By choosing work of the calibre of Michael George's photography and text that will appeal to most of a scholarly disposition we are reasonably confident that our project should survive deaccessioning by future archivists who may be hard-pressed to clear space for new material. We are sustained in this belief by the dedicated work of Robin Darwall-Smith, Univ Historian and Archivist, for whose generous assistance and commitment to this project, we are sincerely grateful.

Graham Diprose was a research-orientated senior lecturer and Lead Tutor in the Faculty of Design at London College of Communication (formerly LCP) 
from 1984 to 2011. Graphic Design students were far more impatient to embrace pioneering digital imaging than most of the Photography Degree staff and students in the School of Media. Graham's love of the River Thames initially led to a project in 1996 with Charles Craig, (former Dean of Media, LCP) and Mike Seaborne (former Senior Curator of Photographs, Museum of London) to remake a 1937 black-and-white panorama, rediscovered among the Port of London Library and Archive Collection, covering over five miles of each bank of London's Docklands, from The Pool of London to The Royal Naval College, Greenwich.

Since digital technology was then in its infancy, Fujicolour UK kindly agreed to sponsor the London's Riverscape project with the loan of their $6 \times 17 \mathrm{~cm}$ panoramic camera and providing us with 500 rolls of 120 Fujichrome 100 transparency film.

We became concerned that the 60-year-old silver gelatine original prints might well outlast our brand new colour dye film images. Hence, we also shot the entire project in black-and-white, on large format 5" $\times 4$ " Delta 400 film, sponsored by Ilford Imaging Ltd. We then commissioned expert monochrome printer, Max Ferguson, to make us a full set of over 500 archival-quality darkroom prints.
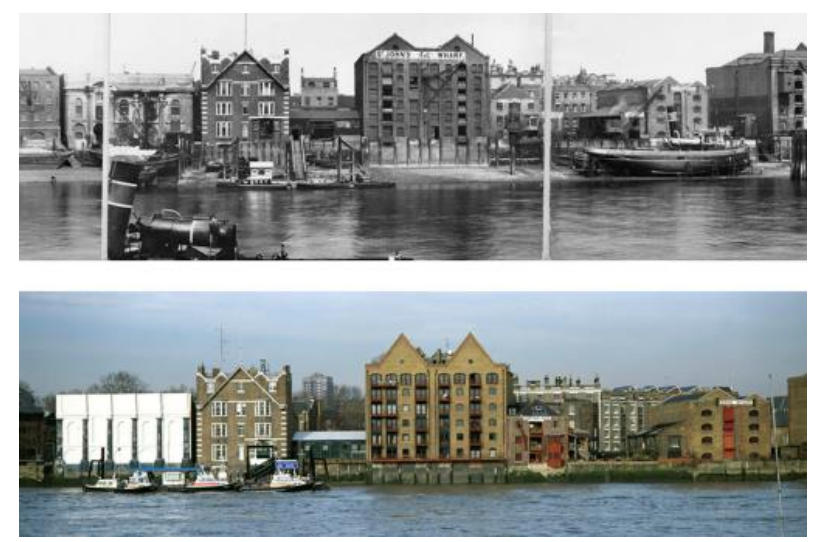

Figure 3: London's Riverscape, Wapping waterfront section from the 1937 \& 1997 silver gelatine $B$ \& $W$ and Fujichrome 100 colour transparency dye-based images.

In 2007, ahead of the Port of London Authority's centenary in March 2009, the London's Riverscape photographers were once again approached by Alistair Gale, Director of Corporate Affairs for the PLA, to 'update' the 1997 panorama. A quick survey on a tripping boat soon revealed that almost everything in the past ten years had changed, as had the quality of digital image technology. We resolved to make a totally new digital panorama, details of book concerning this new part of the project can be found in the References section. We also used this opportunity to re-digitise the 1937 panorama, not by using a scanner this time, but rather re-photographing each sheet with a high resolution (22Mb) Leaf Camera back and lens with close-up extension rings. This achieved a greatly improved quality. This principle developed into the successful technique employed in digitising 400 of Michael George's 35mm transparencies.

One of the PLA managers asked us if the three panoramas, black-and-white 1937, Fujichrome film 1997 and new digital 2007 were likely to survive and be available for the PLA bicentenary in 2109 .

Our answer was probably the opposite of what he expected. The one most likely to make it to 2109 , was, of course, the silver gelatine B\&W 1937. Less likely because of dye-fading and 'vinegar effect' cellulose degradation, was the 1997 colour film version. There was no guarantee that any of our new digital data images in the Museum of London would be safe for even fifty years. In terms of archives, we were all going backwards. We explained the problem to the PLA, who offered to sponsor us to make an exact pigment-ink-printed replica of the 1937 panorama from our digital files.

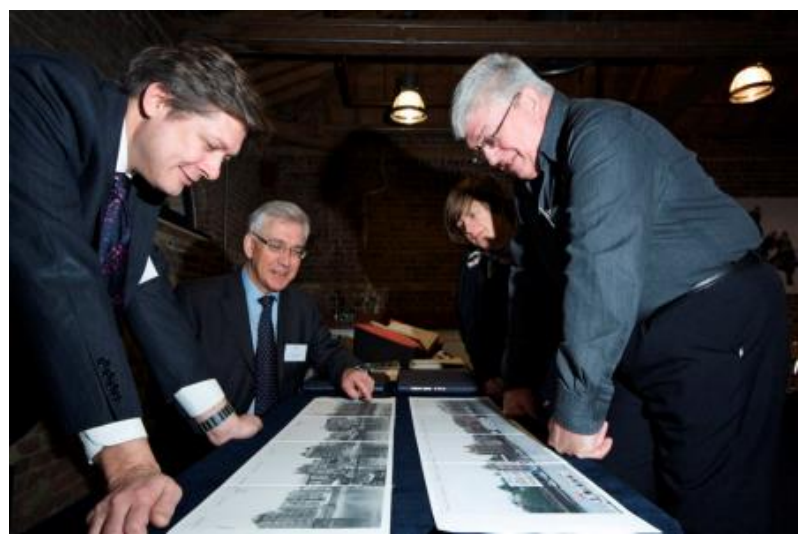

Figure 4: Graham Diprose with David Spence, Director, Museum of London, Docklands (left) and Richard Everitt CBE, CEO of the Port of London Authority, comparing a section of the original 1937 silver gelatine panorama and our new 2007 pigment-ink-printed digital version.

In another River Thames project (1997-2006), Graham Diprose, together with Jeff Robins, were sponsored by English Heritage and the Environment Agency to revisit over hundred 'tripod spots' of Henry W. Taunt. "...in the footsteps of Henry Taunt" is archived by English Heritage, and also as a 'Viewfinder' photo essay on their website. Our new digital images are also archived by Oxfordshire County Library and River \& Rowing Museum at Henley-on-Thames. In each case, the agreed accession included a full set of pigment ink A3 digital prints from our new photography, as well as image data files. We certainly could not risk the possible ignominy, with future generations of scholars, of finding that Henry Taunt's Silver Gelatine prints dating from the 1880 s outlasted our cutting-edge digital images from 2007. 
For many years, the Victorian photographer was based at 9 \& 10 Broad Street, Oxford. Later, from February 1895, he had premises at High Street, number 34, almost directly opposite University College!
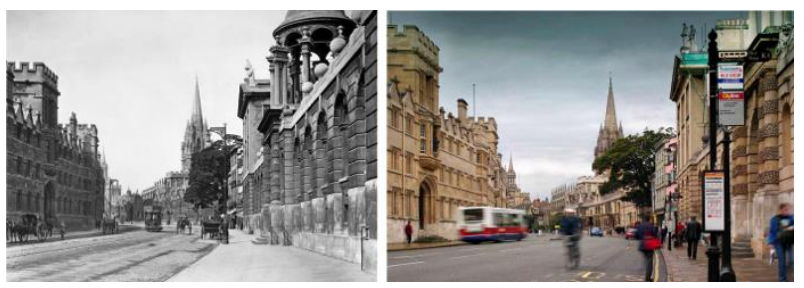

Figure 5: Oxford High Street and University College by Henry Taunt c. 1895, revisited by Jeff Robins and

Graham Diprose, 2007.

It is important here that we acknowledge the vital contribution to the project of Beth Emanuel, word processor and copyeditor. Beth has prevented us from perpetuating innumerable errors in spelling, punctuation, and even plain fact, which otherwise may have worked their way into the Univ archive.

Initially, Michael George wrote captions for each image, varying from a few short words to lengthy paragraphs, many of these contained unusual and, in some cases, obscure and unpronounceable Irish place names. There was also the complicating factor that the plants that are so often the subject of Michael George's photography had to be correctly given their scientific names, in Latin.

Quite early in the project, we all realised that we could assist Robin Darwall-Smith's task immensely if we actually wrote the full Univ accession number and code against each printed image, each caption text in Word, and each digital tiff filename.

An often-overlooked aspect for any artist who is considering archiving their work is to ensure that any accession process is made as simple as possible. By way of example, we would cite UC:PC351/3/P1/032 where:

\section{- UC is University College Oxford}

- PC351 is a reference to Alumnus Michael George

-3 is his photographs and texts of Ireland

- P1 is Munster Province: Clare, Cork, Kerry, Limerick, Tipperary, Waterford

-032 is the number of the image and its related caption or historical text

We hope that by presenting Robin with sheets of conservation images correctly numbered for his system and data image files, named with exactly the same accession number, we will have made it comparatively easy for him to accept Michael George's work straight into Univ's archive.

There were a couple of unexpected problems with our workflow. Michael George had originally numbered his 400 images by county in alphabetical order. It then became clear that, for the sake of simplicity, it would make better sense to reorder the work within each of the four historic provinces of Ireland. As a consequence, every image and text had to be renumbered throughout, a process that required Beth to ensure that the captions and images matched.

The second issue was technical in nature. Whenever texts from Word were copied into Adobe Photoshop, the italic of the Latin names was lost. Carriage returns also had to be added, to copy-fit the text, risking cutting of a first or final letter on a line, or erasing punctuation. The only solution to this unanticipated problem in our workflow was to email Beth a reduced-size JPEG of each of the 150 sheets to check for any additional late errors, prior to printing.

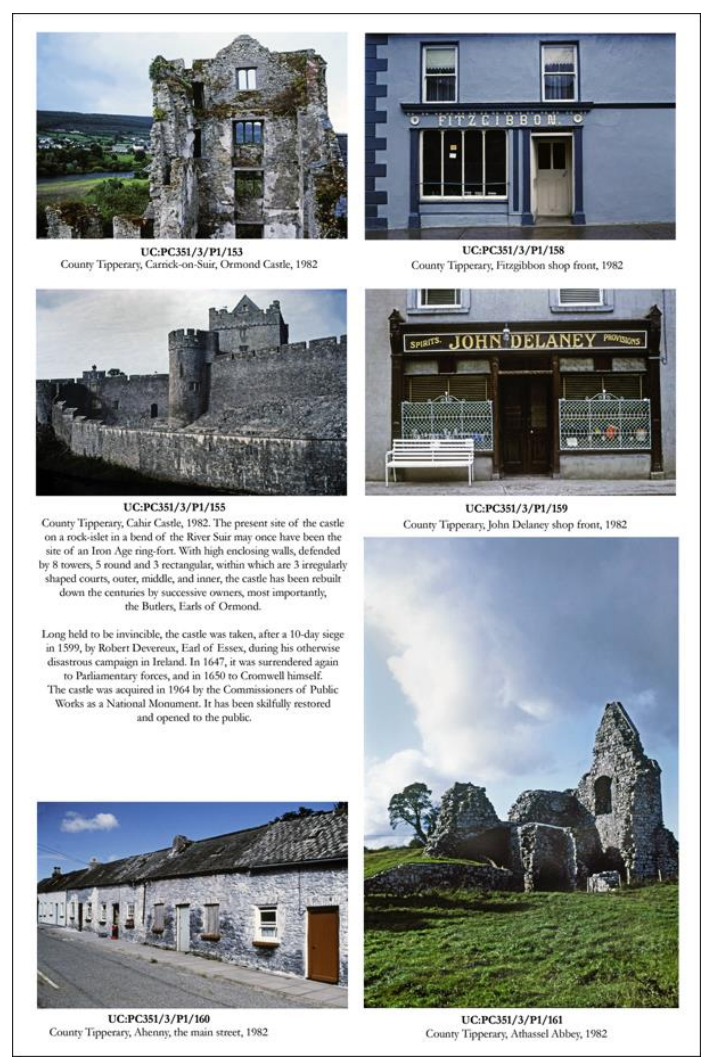

Figure 6: One of the finished sheets for the archive, $35 \mathrm{~cm}$ (13.77 inches) by $23 \mathrm{~cm}$ (9.0 inches). This size was used because we measured Univ's archive boxes to ensure our sheets would fit perfectly.

\section{ALTERNATIVE TO SLIDE SCANNERS}

Around 1973, Bowens, an English studio flash manufacturer, invented the Illumitran to make quality duplicate transparencies. The original slide 
sat on a thick lightbox that contained both a modelling light and flash tube. A $35 \mathrm{~mm}$ camera, Nikon, Canon or any other, was attached onto a rigid bar directly over the top, then using macro lenses or extension rings to achieve 1:1 focusing. Kodachrome originals are particularly difficult to copy even using today's sophisticated top-range scanners as the unusual cyan dye tends to clash with the infrared 'digital ice' anti-dust beam forming strange patterns and artefacts. Any modern scanner used on Michael's slides, whatever the settings, was also unlikely to be able to hold the highlight detail in clouds or contents of the deep shadows that Kodachrome could capture. This $35 \mathrm{~mm}$ film is remarkably sharp by comparison with Kodak Ektachrome or Fujichrome and our method needed to be able to capture this additional detail.

Having used an Illumitran in the 1980s Graham's answer was to develop a hybrid solution, taking the very best of these successfully established traditional workflows, and the quality and ease of use of modern digital equipment and techniques.

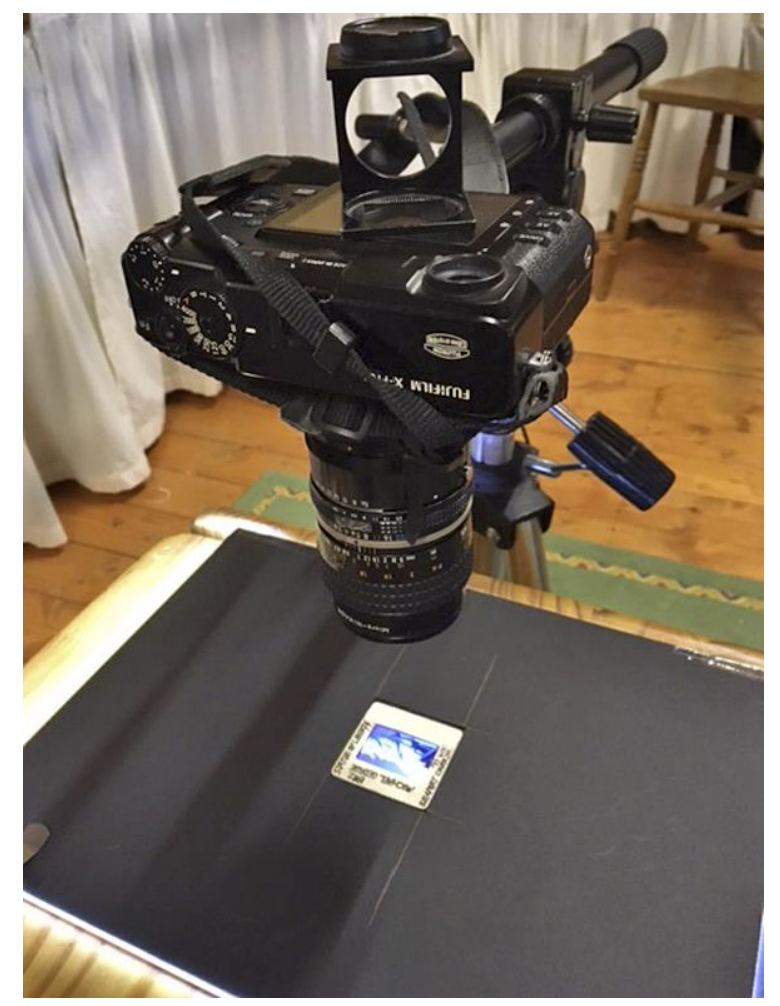

Figure 7: Using a digital camera to scan difficult slides.

The digital camera body used was a Fuji X-Pro 1 $16.5 \mathrm{mb}$ with a Fotodox Nik-FX adaptor to take Graham's 1979 Nikkor 55mm f2.8 Macro lens with its own dedicated extension. This is still considered to be one of the sharpest close-up lenses ever made. Since the lens was designed for coverage of $35 \mathrm{~mm}$ film $(36 \mathrm{~mm} \times 24 \mathrm{~mm})$ and the smaller Fuji XTrans CMOS chip is in APS-C format $(23.6 \mathrm{~mm} \times$ $15.6 \mathrm{~mm})$, this combination only uses the 'centre' of the lens, with the advantage of minimal aberrations and distortions compared to a full-frame camera.

Fuji claim that the new X-Trans CMOS filter array surpasses colour quality and sharpness of many more expensive full-frame digital cameras on the market, and the results of this project certainly appear to endorse this view. By setting the camera to 400 ISO, it was possible to double up the dynamic range from 100 to 200 , to hold far more shadow and highlight detail. The Fuji X-Pro 1 chip suffers no discernible noise, or loss in quality, until well above 800 ISO, hence these are the most advantageous settings. The light box was a $£ 40$ LED Min-Sun model from Tesco. Graham found that light source produced best colour with Camera Fluorescent 2 WB setting, but for other products, running a few simple trial-and-error tests could find whichever needed least correction in Photoshop.

The lens had to be manually opened up to F2.8 to accurately focus on the slide, and was then shut down to either f8 or $\mathrm{f} 11$ for optimum sharpness, to shoot. This only needed repeating from time to time and not for each slide. The shutter speed with this set up was around $1 / 15^{\text {th }}$ second, so a cable shutter release was used to avoid camera shake.

We discovered it was best to underexpose by one stop to hold critical highlight detail and correct this, along with a very manual and time-consuming dust removal in Adobe Photoshop. For many images words like "restore" or "rebuild" would be a far better description that 'spotting out' engrained dust.

If the very highest possible quality was required, one could use a newer Fuji X-Pro $224 \mathrm{mb}$ camera, with the advantage of newer CMOS technology in the same $23.6 \mathrm{~mm} \times 15.6 \mathrm{~mm}$ chip size, and also by shooting Raw, and using non-destructive editing in Adobe Lightroom. However, we were mindful of Robin's concerns that Univ only had a limited space for storing large digital image files. From our X-Pro-1 45mb camera jpeg, in Adobe Photoshop, we made each image $24 \mathrm{~cm} \times 36 \mathrm{~cm}$ at $300 \mathrm{dpi}$, as a $35.5 \mathrm{mb}$ uncompressed tiff. We decided against using any LZW compression on files made for long term archiving, as it is unlikely to receive long-term on-going software support.

\section{CHOICE OF INK JET PAPER, PRINTER \& INK}

We had already carefully measured the standard archive boxes on our first visit to Univ, as $38.0 \times$ $25.4 \mathrm{~cm}$. We decided to make our printed sheets a little smaller in length, for ease of lifting out to remove or review, with reduced risk of damage.

Our chosen ink jet paper has been Canson Rag Photographique in $210 \mathrm{gsm}$ thickness. By using this 
thinner media, the 150 sheets from 'A Journey through Ireland' only take up three inches out of the five-inch-deep boxes. Hence a further Michael George project can be added in due course. The paper itself is $100 \%$ cotton, smooth, matt and totally acid-free. It contains no chemical whitening agents and is fully compliant with ISO 9706 concerning tear-resistance and lack of oxidation. It has an additional barrier layer of a naturally-found substance, below the surface that prevents either colour pigment molecules, or the glycol-based ink carrier from migrating further into the paper, or affecting the images stacked below. Thus, this particular inkjet paper has one of the very highest archival specifications yet devised. For the less scientifically minded, it is also acknowledged to have one of the highest available Dmax (deepest blacks) of any rag or matt paper on the market. More significantly for this project, it is especially optimised for pigment ink printing, such as the 12 HP Vivera inks that we have used in our own HP Z3100 A1 digital printer.

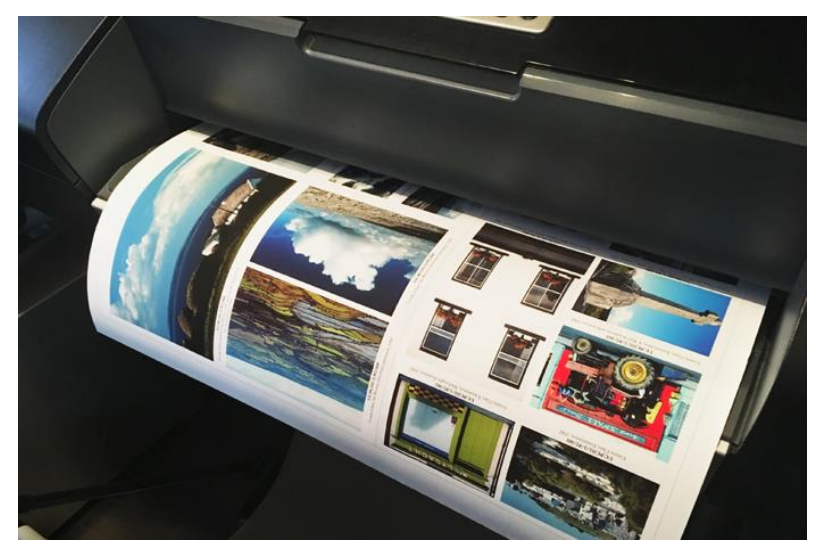

Figure 8: HP Z3100 A1 Pigment ink printer with print.

Graham's HP Z3100 printer was originally a loan machine to print the "...in the footsteps of Henry Taunt" exhibition, but shortly afterwards, we needed to retain it to make the new digital panoramic archive for London's Riverscape and "relatively legally", it was never returned to HP. It is interesting that this piece of technology, now over 10 years old, is to this day, considered among the most archival of all inkjet printers available.

The HP Z3100 only uses pigment inks throughout, unlike some other companies' recent machines that attempt to mix dyes and pigments in the same inkset. There are 12 cartridges each containing $130 \mathrm{ml}$ of ink: gloss enhancer, gray, blue, green, magenta, yellow, light magenta, light cyan, photo black, light gray, matt black, and red. Today, there are printers with higher resolutions than this HPs $1200 \times$ $1200 \mathrm{dpi}$, but this is mainly because dye molecules can be smaller than pigment ink-drops.
It uses 'Bubble Jet' technology, more suited to these larger pigment droplets, rather than the Piezo system common in dye-based Epson printers. The main advantages of this system are that the HP printer-heads need much less cleaning and thus use far less ink, a huge advantage if printer usage is over an irregular timescale. There are also some concerns that, with coarser-fibre rag papers, by making the ink molecule too small, risks causing random longer-term migration through the fibres of paper interior, affecting the image on the surface.

The HP Z3100 has a further advantage over many competitors, of simple internal paper profiling, by printing out 300 coloured dots onto a new paper, and then hanging it out of the front of the printer for ten minutes, for any changes as it is drying.

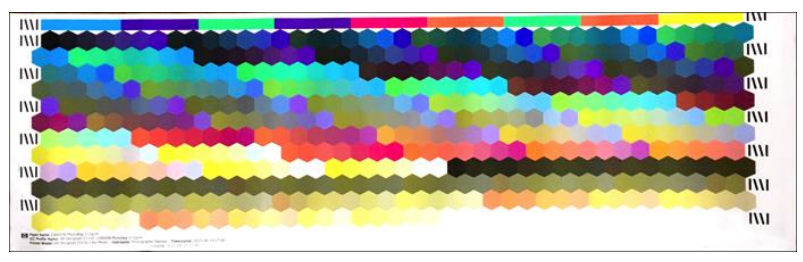

Figure 9: HP Z3100 A1 printer self-profiling system.

It then has a built in GretagMacbeth densitometer that reads back each dot and constructs a bespoke profile for that particular paper. Generally, these last for six months to a year, longer with a stable setup.

\section{COMPILING THE IMAGES AND TEXT ONTO THE ARCHIVAL INK JET PAPER}

Archive sheets were compiled into sets of five, so that they would fit a larger sheet with minimum waste. A one pixel black stroke was added to each tiff file sheet before they were copied onto this larger sheet in Adobe Photoshop, to ensure accurate butting up and also for ease of cutting.

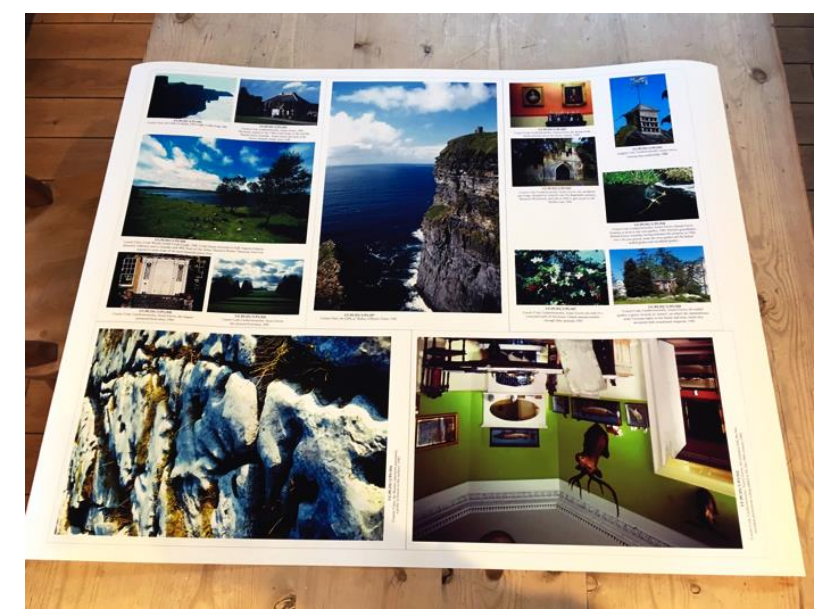

Figure 10: Five sheets for archive, combined into one $60 \mathrm{~cm} \times 76 \mathrm{~cm}$ sheet for printing, minimising paper wastage. 
One of our other concerns with present-day practice is that many archivists tend to give equal weighting to all the images that they are attempting to preserve. While the Archivist of Univ in year 2518 may well have their own opinions, surely it is valuable for the actual living artist to indicate their own favourite, or more significant pieces? By printing in four different sizes, we are suggesting which images, are most significant. However, even the smallest size of $10.4 \mathrm{~cm} \times 6.92 \mathrm{~cm}$ should still be suitable for most screen-based usage, even if much higher resolution is available in the future.

The next two sizes, $15.5 \mathrm{~cm} \times 10.4 \mathrm{~cm}$ and $21.3 \mathrm{~cm}$ $\times 15.5 \mathrm{~cm}$, might also be useful again for very-highresolution large screens, or printed matter, once retrieved by whatever may be the technology of the day. Finally, should Univ decide to hold a Michael George retrospective in the year 2518 or 2718 , all the larger size $32.7 \mathrm{~cm} \times 21.3 \mathrm{~cm}$ prints will copy up by at least $100 \%$ to make high-quality A3 or $12 " \times 16$ " prints for the exhibition. However, the principal is, that the artists, or curators of today, by choosing different sizes, actually have a critical 'say' in how individual parts of the work are received, centuries from now.

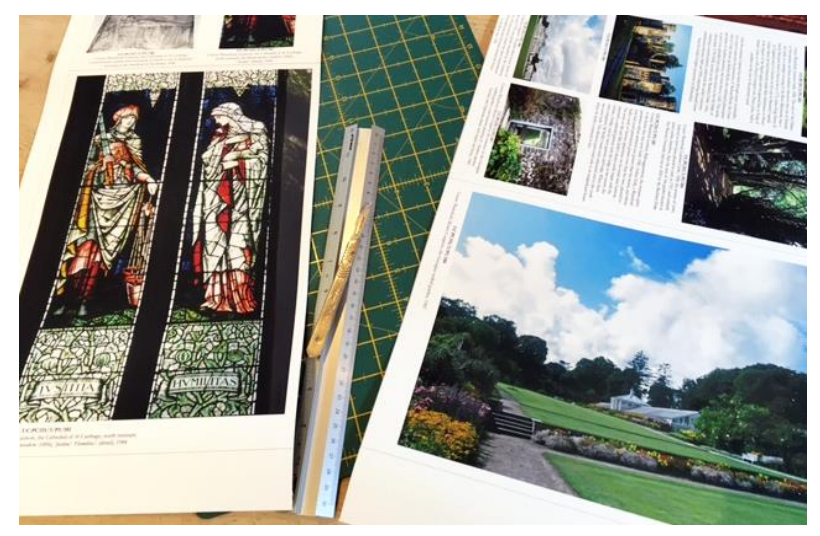

Figure 11: After a couple of days of drying off and hardening, prints were cut into separate sheets along the stroke marks using a sharp scalpel and cutting mat.

One of the only negative aspects of using rag papers and pigment inks, is that the surface can be quite easily scuffed and damaged. It is therefore advantageous to ensure the minimum of handling between printing, cutting up, stacking, and delivery to go into the final Univ-dedicated archiving box.

\section{RETRIEVAL OF OUR IMAGES AND TEXTS MANY CENTURIES FROM NOW}

The only real certainty is that this is one experiment where none of the partners will be around to see its success or failure. An HP Z3100 digital printer spraying minute droplets of accurate pigment colours onto archival paper, at the command of an inanimate computer, would be utterly beyond the comprehension of any $14^{\text {th }}$-century monk that painted Univ's The Apocalypse Manuscripts. Similarly, all the processes used by Univ scholars centuries from now would appear utterly alien to us.

Many of today's archivists are placing blind faith in the ability of our yet unborn, great-grandchildren curators, to have the technology, finances and even the inclination, to migrate our own 'born digital' files into utterly new forms of hardware and software, such as biologically-grown computers storing data on strings of DNA in a century from now. We should check that, if we intend to send digital printed images and text, centuries into the future, it is possible, at least using present-day methodology, to recover an accurate rendition.

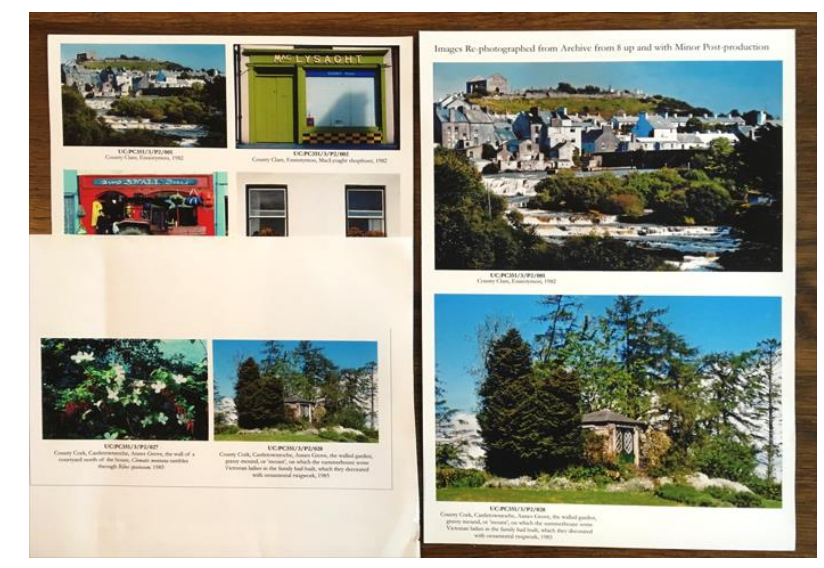

Figure 12: Two of the smallest $10.4 \mathrm{~cm} \times 6.92 \mathrm{~cm}$ images copied using the Fuji X-Pro-1 and 55mm Macro Nikkor and enlarged successfully to double their original size.

Since Jeff Robins and Graham Diprose wished to include large sections of Taunt's history and commentaries in their own book and exhibition, we decided to learn the skills of OCR (Optical Character Recognition). Henry W. Taunt originally printed his 1888 Illustrated Map of the Thames, using a typically Victorian 'Times' Serif font and we soon discovered that OCR software produced much more accurate results with serif faces than sans serif. Although the Z3100 and Canson Rag paper gave a very sharp dot in any case, we decided to use a reasonable size of font and chose serifed 11-point Garamond, as it seemed reasonably compatible in all the different versions between Windows Word and Mac Photoshop.
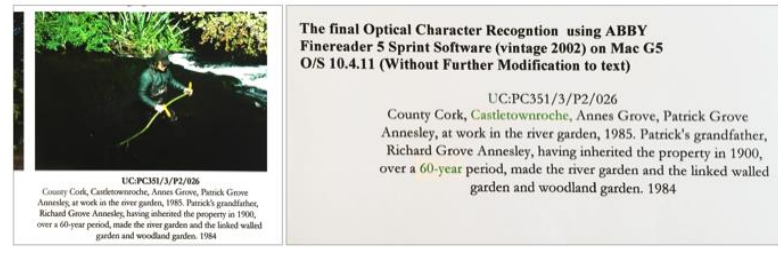

Figure 13: An original small size print and context flatbed scanned as a .tiff file then run though 15-year-old OCR software, gives almost perfect results. 
Apart from a long Irish town name and "60-years", retrieval was $100 \%$ accurate. We chose old OCR software, because it was at hand and to make the exercise a more challenging test. We had now proved that we could retrieve both a high-quality photograph into a very acceptable print $100 \%$ larger. Also we could take text that Beth had printed in Word, copy it into Photoshop, print it (add 500 years sleeping among the dreaming spires here, if you like), copy it, OCR it and end up with a very accurate caption in Word again.

\section{HOW TO SET UP YOUR WORKFLOW}

This workflow and conservation solution, by its very nature, can only hope to save a very small part of any collection. We may finally preserve no more than 1 or $2 \%$ of all Michael George's lifetime's photographic work. It is, however, an extremely good 'insurance' that, at least, something survives.

A well-funded institution, or one applying for a grant, may have a policy to purchase entirely new equipment, perhaps sharing among a small group of museums, galleries or education establishments.

\subsection{Buying new equipment}

Approximate costs, if buying all new inc. VAT:

Camera Fuji X-Pro 2 \& 35mm f2 Lens $£ 1,950.00$

Macro 60mm f2.4 Lens \& MCEX extn. $\quad £ 750.00$

Tripod Manfrotto Compact

Velbon V4 90' Boom Arm

$£ 60.00$

Mini Sun A3 Slim LED Lightbox

$£ 50.00$

HP Designjet Z3200pc Printer

$£ 4,680.00$

$\overline{£ 7,540.00}$

\subsection{Buying s/h setting up on a budget}

Approximate costs, if buying all $\mathrm{S} / \mathrm{H}$ :

Camera Fuji X-Pro $1 \& 35 \mathrm{~mm}$ f1.4 Lens $£ 580.00$

Macro Nikkor 55mm + M2 Extn Ring $£ 160.00$

Tripod Manfrotto Compact $\quad £ 50.00$

Velbon V4 90' Boom Arm $\quad £ 60.00$

Mini Sun A3 Slim LED Lightbox $\quad £ 50.00$

HP Design-jet Z3100pc Printer refurb. £1,200.00

$\overline{£ 2,100.00}$

\subsection{Materials cost - either of above}

Roll of Canson Rag Photographique $210 \mathrm{gsm} 15 \mathrm{~m} \times 24$ inches

$£ 120.00^{*}$

*this project took 2.3 rolls

HP No 70 inks (vary with colour) £80.00*

*we used one ink cartridge per roll of paper

Pro-printing 150 sheets METRO Lab £13,950.00*

*for lab printing this project on similar paper \& inks

\section{REFERENCES}

Darwall-Smith, R. (2008) A History of University College, Oxford. Oxford University Press.

Diprose, G., Craig, C., and Seaborne, M. (2009) London's Changing Riverscape: Panoramas from London Bridge to Greenwich. Frances Lincoln, London.

Diprose, G., and Robins, J. (2007) The River Thames Revisited: In the Footsteps of Henry Taunt. Frances Lincoln, London.

George, M., and Bowe, P. (1986) The Gardens of Ireland. A New York Graphic Society Book/Little, Brown \& Company, Boston.

Image Permanence Institute (2018) Acetate Film Base Deterioration - The Vinegar Syndrome. Rochester Institute of Technology, New York. https://www.imagepermanenceinstitute.org/resourc es/newsletter-archive/v12/vinegar-syndrome (retrieved 5 January 2018).

Library of Congress (2018) How Long Will Digital Storage Media Last?

http://www.digitalpreservation.gov/personalarchivin g/documents/media durability.pdf (retrieved 19 March 2018).

McKendrick, J. (2012) Apple Co-Founder Steve Wozniak Distrusts the Cloud: Is He Right? Forbes, 5 Aug 2012.

https://www.forbes.com/sites/joemckendrick/2012/0 8/06/apple-co-founder-steve-wozniak-distrusts-thecloud-is-he-right/ - 6049724e6042.

Ortiz, M., Mikkilineni, V., and Aravind, K. (2007) Paper Inkjet Forensics. Purdue University School of Electrical and Computer Engineering, Lafayette, Louisiana, USA.

https://engineering.purdue.edu/ prints/outreach/ED EWG06.pdf (retrieved 19 March 2018).

Van der Werf, B. (2011) Bit Rot \& Long Term Access. Open Preservation Foundation.

http://openpreservation.org/blog/2011/02/28/bit-rotlong-term-access/ (retrieved 19 March 2018).

Wilhelm Imaging Research (2007) HP Design-jet Z3100 Print Permanence Ratings, 28 December 2007. Wilhelm Imaging Research. http://wilhelm-research.com/hp/Z3100.html (retrieved 19 March 2018). 